\title{
Infracciones penales en espacios transfronterizos. El narcotráfico en la provincia del Tamarugal, Chile ${ }^{1}$ Alejandro Corder Tapia* y Viena Ruiz Tagle**
}

\section{Resumen}

Este trabajo da cuenta de la situación del narcotráfico en la provincia del Tamarugal durante los años 2003 a 2010 a través del análisis de estadísticas delictivas de instituciones de control penal (Ministerio Público y Gendarmería) y policiales (Carabineros y Policía de Investigaciones de Chile). El análisis de la situación del narcotráfico se hace situando la problemática del tráfico de drogas en el contexto internacional de la globalización y de la emergencia de espacios de frontera que no responden necesariamente a la definición tradicional de los Estadosnación. El trabajo se propone situar esta problemática delictual en los procesos de orden mundial, atendiendo a las características específicas de la región de Tarapacá y su condición de espacio transfronterizo, así como al contexto regional y los esfuerzos de orden internacional por controlar el tráfico ilegal de estupefacientes.

Palabras clave: narcotráfico, drogas, frontera, redes criminales, Tarapacá.

\section{Abstract}

This research addresses the drug trade in Tamarugal Province for the years 2003 to 2010, through an analysis of crime statistics from the police (Chilean Carabineros and Police Investigations Unit), and penal system institutions (National Prison Service and the Office of the Prosecutor). The analysis of the drug trade situates the drug trafficking issue in the international context of globalization and in a border area emergency that does not necessarily correspond to the traditional definition of the nation state. The research proposes to situate this issue of criminal offence in the context of the international legal order, focusing on the specific characteristics of the Tarapacá region and its condition as a trans border territory. It also proposes to situate this issue in a regional context, as well as in terms of the efforts of the international order to control illegal trafficking of drugs.

Keywords: drug trade, drugs, border, criminal networks, Tarapacá.

1 Este trabajo es producto del proyecto interno Di 0064/09 titulado "Infracciones penales en espacios de frontera. El narcotráfico en la provincia del Tamarugal, años 2000-2009", financiado por la Dirección General de Investigación de la Universidad Arturo Prat de Chile. Asimismo, esta investigación se ubica en el marco del Proyecto ECOs-Conicyt C008H02 ¿De región marginal a región pivotal?: La triplefrontera andina (Perú, Bolivia y Chile). Dicho proyecto ha sido ejecutado por el Instituto de Estudios Internacionales (INTE) de la Universidad Arturo Prat (UNAP) y el Instituto de Geografía Alpina de la Universidad Joseph Fourier, Francia.

* Investigador del Instituto de Estudios Internacionales (INTE), Universidad Arturo Prat. Correo electrónico: alejandrocorder@gmail.com

** Asesora jurídica regional de la Defensoría Penal Pública Región de Arica y Parinacota. Correo electrónico: gabogada@gmail.com 


\section{Introducción}

La preocupación por parte de las agencias estatales sobre la problemática del consumo de drogas ha tenido una expresión concreta en una institucionalidad pública dedicada exclusivamente a enfrentar el problema del consumo y tráfico de drogas, lo cual ha ido aparejado de modificaciones legislativas orientadas a controlar y sancionar el consumo y tráfico ilegal de estupefacientes (la creación del Consejo Nacional para el Control de Estupefacientes [Conace], actual SENDA, y la promulgación de la Ley 20000 , entre otros hechos). Estas iniciativas estatales reflejan la preocupación por el aumento en los decomisos de drogas (como lo consignan las estadísticas policiales) así como por el número de personas detenidas y condenadas por estos hechos. En este marco, resulta importante situar la problemática del tráfico de drogas en relación con la condición de país fronterizo con dos de los mayores productores de cocaína del mundo como lo son Perú y Bolivia para comprender en su real dimensión la situación del narcotráfico en el norte de Chile.

El objetivo de este trabajo es situar la problemática del narcotráfico en el contexto de un espacio de frontera como lo es la región de Tarapacá, teniendo presente sus particularidades históricas y los procesos de orden mundial que inciden en el problema analizado. Para ello, la metodología de trabajo utilizada es el análisis de estadísticas policiales sobre narcotráfico, de población penal de la provincia del Tamarugal en Tarapacá y del accionar del Ministerio Público a través de la Fiscalía Local de Pozo Almonte.

Este trabajo se organiza como sigue: una primera parte caracteriza a la región de Tarapacá como una región fronteriza entregando antecedentes históricos que permiten definirla como tal. La segunda parte aborda desde un ejercicio teórico los procesos de orden transnacional y su impacto en la región discutiendo los conceptos de globalización y frontera. La tercera y cuarta parte aluden a la caracterización del tráfico de drogas a escala mundial en América Latina y la respuesta que se ha dado a través de organismos internacionales, para luego analizar la situación en Chile. A continuación se efectúa el análisis de las estadísticas policiales relacionadas con tráfico de drogas, población penal e información otorgada por el Ministerio Público (órgano persecutor penal en Chile). 


\section{El espacio transfronterizo de Tarapacá}

La configuración de la región de Tarapacá como un espacio transfronterizo tiene profundas raíces históricas asociadas al habitar de pueblos indígenas en la región (aymaras, quechuas, etc.) (Murra, 1984, 2002). Es así como es posible encontrar yacimientos arqueológicos con objetos propios de diferentes pisos ecológicos que eran movilizados o intercambiados por los diferentes grupos que habitaban la zona desde el altiplano hasta la costa. En tiempos precolombinos, Tarapacá constituía un territorio con múltiples flujos e intercambios de bienes y personas que daban cuenta de la diversidad de espacios habitados en la región (Briones, Núñez y Standen, 2005:13). ${ }^{2}$ Así, pueblos indígenas como los aymaras habitaban el altiplano y los valles de la región, generando procesos de intercambio con pueblos de la costa; estos hechos son recogidos en investigaciones arqueológicas que no sólo se remiten a la actual región de Tarapacá, sino a la amplitud del desierto de Atacama, partiendo desde la actual región de Arica y Parinacota, como lo describen Sepúlveda, Guevara y Briones (2005) cuando relacionan el tráfico de caravanas y el arte rupestre que es posible encontrar en esa zona del norte de nuestro país, particularmente la Quebrada de Suca:

Coincidimos en que las representaciones de caravanas pudieron ser manifestaciones votivas relativas al éxito de esta actividad humana (las caravanas) (Núñez, 1985; Van Kessel, 1976). En este contexto, incluso podríamos anticipar que la asociación de tales diseños icónicos con otros ampliaría nuestro conocimiento del imaginario visual del caravanero prehispánico. Otras manifestaciones rituales serían los depósitos en formas de cajas, la formación de apachetas y las quemas de ofrendas, algunas de las cuales aún siguen vigentes (Lecoq, 1987; Nielsen, 1997; Núñez, 1976; entre otros) (2005:228).

${ }^{2}$ Así concluyen en su trabajo Briones, Núñez y Standen: "La dinámica de estas relaciones macroespaciales permitió afianzar el desarrollo cultural y económico de la sociedad tarapaqueña, y en este aspecto, el oficio y las redes caravaneras desempeñaron un rol significativo. El traslado e intercambio de bienes entre los valles, oasis, litoral y altiplano, a través del tráfico caravanero, implicó no sólo transacciones económicas, sino también la generación de complejos procesos de la visualización del poder, creatividad simbológica, ritualidad compartida e integración de territorios étnicos vecinos" (2005:221). 
Este rico proceso de integración e intercambio cultural, social y económico sustentó las bases de un espacio andino que luego de la constitución de los Estados nacionales siguió operando, pero con una distribución del territorio que reflejaba la lógica de fronteras nacionales. Es en este espacio territorial y social en el que el pueblo y la cultura aymara, particularmente, han tenido un papel protagónico en los intercambios transfronterizos. Como señala Gundermann, en relación con la etnia aymara,

[...] la consecución de bienes productivos o simbólicos provenientes de distintos pisos ecológicos disponibles en otros sectores geográficos, los obligó a articular o articularse con otros espacios, recurriendo a prácticas simples o complejas de intercambio o de acceso directo a recursos con o sin control central. En ambas situaciones, para poder hacer uso de ellos, grupos o familias debieron tener un conocimiento muy profundo de los diferentes espacios geográficos entre los cuales circulaban las personas y los objetos (Gundermann, 1999).

La reconfiguración del territorio de Tarapacá y Antofagasta con posterioridad al término de la Guerra del Pacífico tuvo importantes consecuencias en las comunidades locales como Iquique, Tacna y Arica, que estuvieron en litigio en tanto exprovincias peruanas antes del inicio de la guerra, particularmente las dos últimas, luego del fin del conflicto armado (iniciado en 1879 y concluido en 1883). Los procesos de "chilenización compulsiva” (González, 2004) en los territorios de Tarapacá, Tacna y Arica entre 1910 y 1922 son expresión de las nuevas lógicas de frontera que se impusieron en este territorio. Así también lo son, por el contrario, la participación de las huelgas de trabajadores del salitre impulsadas a principios de 1900 y que tienen como ícono de las demandas obreras la matanza en la escuela Santa María de Iquique el 21 de diciembre de 1907, donde, como relata Devés en su libro sobre la señalada masacre obrera, trabajadores peruanos y bolivianos eran parte de las agrupaciones de trabajadores salitreros que demandaban mejoras en las condiciones de vida y trabajo: "En el centro mismo de la columna destacábanse los colores de las banderas chilena, peruana y boliviana, cuyos pliegues se batían al viento orgullosos, ufanos al ir a la cabeza de ese ejército internacional..." (2002:73). 
Pero no fue sólo una redistribución del territorio, por el contrario, este proceso contrajo la emergencia de nuevas identidades sociales, donde "lo nacional" emergió como un aspecto central, repercutiendo también en los procesos de intercambio ya señalados que hasta ese momento se habían establecido en la frontera. Para el caso de la triple frontera que analizamos, esa centralidad fue construida con base en procesos de constitución de identidades nacionales articuladas en discursos nacionalistas de amigo/ enemigo que impactaron en las relaciones étnicas tradicionales transfronterizas (González, 2006). Así, fueron entonces tanto las comunidades locales como las localidades asentadas en las nuevas fronteras nacionales, las que de manera más significativa tuvieron que adaptarse a las nuevas lógicas de frontera.

Los flujos migratorios regionales son una clara expresión de la conformación de un espacio transnacional, que pese a las lógicas de frontera ha sido un componente definitorio en el desarrollo y la consolidación de esta región como un circuito transnacional. Al respecto, Gavilán y Tapia señalan que "dada su condición de frontera desde la formación de los estados-naciones, Tarapacá se constituyó en un espacio de inmigración y emigración temporal, cíclica y definitiva recurrente" (2006:7). Como lo demuestran estas autoras en su análisis sobre las estadísticas censales de finales del siglo xix y xx, "la proporción de extranjeros de origen fronterizo fueron siempre preponderantes, entre los cuales destacan peruanos y bolivianos. Fue el censo de 1907, el que presentó la mayor proporción de extranjeros a nivel nacional con un 4.2\%, respecto de la población chilena con una cifra absoluta de 132 mil personas" (2006:10).

Actualmente, la presencia de extranjeros sigue siendo significativa, sobre todo los extranjeros de países fronterizos. Así lo demuestran las estimaciones hechas por el Ministerio del Interior sobre la población inmigrante en la región de Tarapacá, donde las estadísticas indican que la participación de extranjeros del total de la población regional es de 6.66\%, la más alta a escala nacional, seguida por la región de Arica y Parinacota con $6.10 \%$ (Chile, G. d., 2010). Complementariamente, la encuesta CASEN 2006 establece que 25\% de población boliviana en Chile reside en la región de Tarapacá, $23 \%$ en Arica y Parinacota y 31\% en la región de Antofagasta.

Hoy por hoy, la región de Tarapacá tiene una población de 238950 habitantes y una densidad poblacional de 5.66 habitantes $/ \mathrm{km}^{2}$, con una 
superficie de $42225.8 \mathrm{~km}^{2}$, que se encuentra dividida administrativamente en dos provincias: Iquique y Tamarugal. Por su parte, la provincia de Tamarugal tiene una superficie de $39390.5 \mathrm{~km}^{2}$ y está conformada por cinco comunas: Pozo Almonte, Camiña, Colchane, Huara y Pica. En esta provincia se encuentra la frontera internacional con Bolivia de más de 300 kilómetros de extensión en los cuales existen sólo tres pasos fronterizos habilitados (Colchane-Pisiga, Apacheta de Irpa o Cancosa y Paso Abra Oriente de Napa).

Así los datos, el espacio transfronterizo de Tarapacá constituye un territorio con particulares procesos de flujos migratorios y de bienes materiales que difiere significativamente de otras regiones de nuestro país, pero que se asemeja a las regiones de Arica y Parinacota y Antofagasta, esto es, el Norte Grande de Chile. Es definitivamente su condición de espacio transfronterizo el que le otorga dicha particularidad, pero a su vez, es un espacio de interés para el análisis del impacto de la globalización, la internacionalización de las regiones y el desdibujamiento de las fronteras nacionales en las comunidades locales.

\section{Procesos transnacionales y su impacto en lo local}

En esta sección se discuten dos procesos que tienen directa relación con las características del espacio transfronterizo descrito con anterioridad: el proceso de globalización y la redefinición de las fronteras. Si bien analíticamente es posible distinguir ambos procesos, en su desarrollo histórico es posible apreciar que ambos confluyen tanto en su devenir como en su impacto en espacios de frontera como los descritos. A su vez, estos procesos han intervenido de manera significativa, especialmente en los últimos 20 años, en el problema del narcotráfico.

El proceso de globalización constituye un fenómeno difícil de delimitar en relación con los aspectos más centrales que lo definen, así como respecto de los efectos sobre la economía, lo tecnológico, lo social o lo político que se entrecruzan y sobreponen permanentemente al tratar de identificar el papel que cada uno de estos aspectos desempeña a la hora de una definición de este proceso (Guillén, 2001). Siguiendo esta lógica, desde un punto de vista económico la globalización puede ser definida como un 
cambio profundo en la economía capitalista, en que los protagonistas de este nuevo sistema económico lo constituyen una serie de corporaciones multinacionales o transnacionales cuya actuación trasciende la frontera de los Estados nacionales (Beck, 2008).

Paralelamente, se puede agregar que este nuevo sistema económico se sustenta en un aumento significativo de los flujos de capitales pero también de los flujos de información, cuya masificación y velocidad de intercambio han impactado de manera profunda o más bien demandado la emergencia de actores internacionales que obligan a redefinir el papel de los Estados-nación y particularmente lo que dice en relación con el ejercicio de la soberanía. ${ }^{3}$

Castells señala que la globalización puede ser entendida también como "el proceso resultante de la capacidad de ciertas actividades de funcionar como unidad en tiempo real a escala planetaria" (1999:2), unidades que hacen referencia tanto a la economía, los medios de comunicación, la ciencia, la tecnología y, también, al crimen organizado; todo lo cual se articula a partir de un nuevo sistema global que tiene la característica, enfatiza Castells, de ser extremadamente incluyente y extremadamente excluyente: "Incluyente de todo lo que tiene valor según los códigos dominantes en los flujos y excluyente de todo aquello que, según dichos códigos, no tiene valor o deja de tenerlo" (1999:4). De esta manera, regiones, actores o segmentos de población pueden ser parte importante de estas redes globales, pero también pueden generar, por ejemplo, que actores de un mismo territorio, un barrio o una ciudad queden excluidos de redes globales por no contar con las características o condiciones para interactuar en dichas redes.

Saskia Sassen (2007), por su parte, sostiene que la globalización no debe entenderse sólo como un proceso de formación de instituciones exclusivamente globales y de la interdependencia creciente de los Estados-nación, sino también como un proceso que reside en el interior de lo nacional; esto es, procesos de cambio que situados en un territorio nacional "forman

${ }^{3}$ Analizando esta problemática, Beck señala (citando a David Held) que "la soberanía propiamente dicha se debe entender y analizar hoy como un poder escindido que es percibido como algo fraccionado por toda una serie de actores — nacionales, regionales e internacionales - y que se encuentra limitado y maniatado precisamente por esta pluralidad inmanente" (2008:65). 
parte de la globalización porque incorporan redes o entidades transfronterizas que conectan múltiples procesos y a actores locales o 'nacionales', o bien porque se trata de cuestiones o dinámicas que se registran en un número cada vez mayor de países o ciudades" (Sassen, 2007:4). Esta mirada resulta particularmente relevante a la hora de comprender cómo la globalización adquiere singularidad para actores o procesos de orden nacional pero que se articulan de manera transfronteriza con múltiples actores o procesos en otros países.

Siguiendo el argumento de la configuración de nuevas "entidades transfronterizas" es que resulta relevante explicitar la concepción de frontera que utilizamos para nuestro análisis, partiendo del hecho de que la reflexión en torno a este concepto no es algo acabado, sino que por el contrario, está en pleno desarrollo. De este modo, podemos identificar al menos tres concepciones de frontera que son atingentes para el problema que aquí analizamos.

El primero de ellos proviene del concepto de Estado-nación en el que la frontera es la delimitación de un territorio que supone una serie de rasgos comunes a las comunidades insertas en él, espacio en el cual, además, el Estado tiene el pleno ejercicio de su soberanía. El aspecto central de esta definición es que la frontera expresa una dimensión geopolítica de la misma. Esta concepción de frontera ha sido foco de importantes cuestionamientos, en razón de las transformaciones que fenómenos como la globalización han producido precisamente en la frontera como delimitador de fenómenos de orden nacional (Guillén, 2001; Medina, 2006). A pesar de la crítica a dicha noción de frontera, ésta continúa operando de manera concreta en el aparato del Estado como en los propios sujetos que la habitan. ${ }^{4}$

Una segunda aproximación al concepto de frontera es aquella que hace énfasis en la dimensión sociocultural de ésta, asociada a la porosidad que puede adquirir este límite nacional reflejado en identidades socioculturales propias de un espacio donde la identidad nacional ha perdido relevan-

${ }^{4}$ En su modelo sociocultural para el estudio de las fronteras internacionales, Medina identifica estas dos concepciones como el subcampo normativo para la primera noción (fronteras políticas, fiscales y administrativas; ejercicio del poder), y para la segunda el subcampo ideacional (representaciones simbólicas, de las identidades culturales; imágenes de las fronteras) (2006:12). 
cia en la construcción de dichas identidades de frontera. ${ }^{5}$ Por lo anterior es que el concepto de frontera pierde fuerza como delimitador y surge como una membrana porosa, que es atravesada por distinto procesos de orden mundial pero que impactan de manera singular en los espacios de frontera. Hacemos mención precisamente a los estudios que ponen su atención en el impacto de la globalización (Grimson, 2004; Sassen, 2007).

La tercera mirada sobre las fronteras es aquella que se sitúa críticamente en las visiones más esencialistas de la frontera, que las conciben como espacios de hermandad o de hibridación generalizada (Grimson, 2004), en el entendido de que los territorios de América Latina anteriores a la formación de los Estados nacionales tuvieron un proceso de continuidad e integración, incluso después de las fronteras nacionales (una especie de integración "por abajo", como señala Grimson). Coincidimos con este autor en el sentido de que es precisamente la instauración de las fronteras nacionales lo que tuvo profundas influencias en las "maneras de sentir, pensar y actuar de las poblaciones ubicadas en las zonas de frontera" (Grimson, 2004:6).

Este marco en el que se discute y problematiza en torno a la frontera como hecho y como definición, da cuenta no sólo de la relevancia teórica del concepto, sino también de las transformaciones que están operando en ella producto de los procesos de orden global, así también como de las dinámicas que los actores de estos espacios fronterizos construyen de manera cotidiana. Tomando posición sobre la discusión señalada, creemos que resulta pertinente para comprender el problema del narcotráfico entender la frontera desde una mirada crítica que más que dar cuenta de procesos de integración, hermandad o hibridación, ha generado profundas transformaciones en la cotidianidad de los sujetos. Asimismo, consideramos pertinente poner atención en que las transformaciones en espacios de frontera son reflejo de procesos de orden global reseñados con anterioridad que repercuten en problemáticas como las que aborda este trabajo.

${ }^{5}$ Alejandro Grimson va más lejos al distinguir entre fronteras culturales y fronteras identitarias "las fronteras de significado y las fronteras de pertenencia" (Grimson, 2004), distinción que permite comprender la complejidad del debate en torno al concepto de frontera y la pertinencia de los estudios transfronterizos. 


\section{El tráfico de drogas a nivel global. Una aproximación a la problemática en Tarapacá}

La situación del tráfico de drogas en Chile y en la región de Tarapacá en particular, no se puede comprender si no se hace en el marco del contexto internacional del tráfico ilegal de estupefacientes.

En el plano de los organismos internacionales, la Oficina contra la Droga y el Delito de la Naciones Unidas constituye uno de los organismos más importantes que intenta construir una política mundial que enfrente la problemática señalada. ${ }^{6}$ Esta organización data del año 1998, cuando producto de una serie de sesiones extraordinarias de la Asamblea General de las Naciones Unidas se asumió la necesidad de trabajar en pos de la eliminación o la reducción significativa de la producción ilícita y el uso indebido de drogas para el año 2008; sin embargo, dado que no se alcanzaron los resultados esperados, el proyecto se extendió por una década más. Así, cada año se elabora un informe que da cuenta de los avances alcanzados a escala mundial y las particularidades que va adquiriendo el tema del tráfico de drogas y los delitos asociados a ella. En el último informe emanado de este organismo se aborda con especial atención los mercados transnacionales de drogas como la cocaína, la heroína y los estimulantes de tipo anfetamina.

En el estudio señalado se sostiene que los mercados ilícitos de opiáceos y la cocaína a nivel mundial son las amenazas transnacionales más graves derivadas de la droga y el delito. En lo que se refiere a la cocaína, el informe señala que "la superficie dedicada al cultivo de coca en el mundo se redujo en un 5\% el último año, de 167600 hectáreas, en 2008 a 158800 hectáreas en 2009. Esa variación obedece sobre todo a una disminución importante en Colombia, no compensada por el aumento registrado en el Perú y en el Estado Plurinacional de Bolivia” (Naciones Unidas, 2011:9). El análisis también sostiene que tanto la producción como el tráfico y el consumo de cocaína han ido variando a través del tiempo. Es así como la producción de cocaína en Colombia se redujo en 58\% en los últimos diez años, mientras que en Perú y Bolivia aumentó en 38\% y $112 \%$ respectivamente. En torno al consumo de cocaína, éste ha tenido una disminución

${ }^{6}$ Para conocer mayores antecedentes sobre esta oficina y su análisis sobre el tráfico de drogas, revísese este link: < http://www.unodc.org/unodc/en/drug-trafficking/index. html>. 
significativa en el número de personas en Estados Unidos (menos de la mitad entre el periodo 1982-2008); pero los consumidores de cocaína en Europa se han duplicado en el último decenio. Lo anterior asociado a los esfuerzos en materia de incautaciones que también han tenido efecto en las pautas del tráfico. El mayor control en Colombia, señala el informe, ha modificado las rutas de tránsito hacia países como Ecuador. Las medidas represivas a los cárteles de la droga mexicanos han llevado a que países de América Central sean utilizados como vía de tránsito.

Son precisamente las medidas represivas tomadas durante los últimos 20 años las que de mejor manera muestran la respuesta que particularmente Estados Unidos y algunos países de América Latina han asumido como estrategia para enfrentar el narcotráfico — ejemplo de ello lo constituyen los grandes recursos asignados a la DEA y las numerosas y continuas modificaciones a la legislación de droga en América Latina, con penas extremadamente duras e incluso vulneraciones a garantías procesales mínimas como el principio de inocencia- Para contextualizar esta estrategia, es importante entregar algunos elementos que permitan comprender el surgimiento de esta política y los resultados que ha tenido a nivel mundial, especialmente en América Latina.

\section{La guerra contra las drogas}

El Plan Colombia, también conocido como Plan para la Paz, la Prosperidad y el Fortalecimiento del Estado, es una iniciativa que nació en el año de 1999 como fruto del acuerdo entre el presidente de Estados Unidos, Bill Clinton, y el presidente de Colombia, Andrés Pastrana, para enfrentar de manera conjunta el problema del narcotráfico. ${ }^{7}$ A pesar de que el

${ }^{7}$ El Plan Colombia, definido por el gobierno de ese país, es "una estrategia integral de cooperación bilateral, cuyo objetivo general es combatir las drogas ilícitas y el crimen organizado, para así contribuir a la reactivación económica y la consecución de la paz en Colombia, al tiempo que se fortalece el control sobre la oferta de drogas ilícitas en las calles norteamericanas. Este acuerdo está basado en el principio de responsabilidad compartida, según el cual se reconoce que el problema mundial de las drogas es una responsabilidad común y compartida por toda la comunidad internacional, que exige una visión integral y equilibrada para enfrentar la demanda y la oferta de drogas ilícitas" (Colombia, 2006:10). 
Plan Colombia tenía inicialmente diez estrategias de acción, ${ }^{8}$ las de mayor alcance e impacto han sido aquellas orientadas hacia la defensa nacional y las de paz frente al conflicto armado que aún vive ese país, así como la estrategia antinarcóticos. ${ }^{9}$ Sobre las primeras, los resultados han sido significativos en la medida en que el gobierno colombiano ha aumentado en los dos últimos periodos presidenciales el control del territorio gracias a la presencia de las fuerzas armadas y de la Policía Nacional; estrategia militar que ha tenido sus frutos más destacados en la muerte de importantes jefes militares de las guerrillas así como en la liberación de personas secuestradas (como por ejemplo Ingrid Betancourt, quien fuera rescatada por el ejército colombiano en julio de 2008, entre otras personalidades colombianas). ${ }^{10}$

Sin embargo, en lo que se refiere a la estrategia antinarcóticos, los resultados o la evaluación de esta política de alcance internacional están lejos de ser positivos. Para varios especialistas en la temática del narcotráfico (Dammert, 2009; De Rementería, 2009; Tokatlian, 2011), la "guerra contra las drogas", la cual no se agota en el Plan Colombia pero encuentra en éste a su más claro exponente, se ha traducido en "políticas prohibicionistas basadas en la represión de la producción y en la interdicción al tráfico y a la distribución, así como en la criminalización del consumo (Sorj, Carvalho, Oliveira y Fernandes, 2009:7)", sin alcanzar los resultados esperados, sobre todo porque América Latina sigue siendo el mayor pro-

${ }^{8}$ Las diez estrategias fueron: una estrategia económica; una estrategia fiscal y financiera; una estrategia de paz; una estrategia para la defensa nacional; una estrategia judicial y de derechos humanos; una estrategia antinarcóticos; una estrategia de desarrollo alternativo; una estrategia de participación social; una estrategia de desarrollo humano; y una estrategia de orientación internacional (Naciones Unidas, 2011).

${ }^{9}$ En términos concretos, el Plan Colombia ha consistido en un fuerte apoyo económico de Estados Unidos para enfrentar militarmente el narcotráfico asentado en Colombia en asociaciones criminales dirigidas al tráfico de drogas y que se han sustentado tanto en el uso de las armas (cárteles colombianos) como en la desestabilización de la institucionalidad política, especialmente durante la década de los ochenta y noventa del siglo xx.

${ }^{10}$ Cabe señalar que de acuerdo con las estadísticas oficiales del gobierno colombiano, los secuestros extorsivos disminuyeron en $85.4 \%$ entre 1999 y 2005 (de 2587 a 378 secuestros anuales) (Colombia, 2006:20). 
ductor de cocaína y marihuana a escala mundial. ${ }^{11}$ En su trabajo Adictos al fracaso, Brian Loveman señala que:

La guerra contra las drogas, mal planeada e implementada en forma deficiente, es una de las razones del fracaso de las políticas de Estados Unidos. La fumigación de cultivos, la intercepción de drogas y el incremento de la asistencia militar y policial (que constituyó el 80 por ciento del Plan Colombia, y que constituía en las políticas impulsadas con mayor fuerza por parte de Estados Unidos), no han producido los resultados deseados por los policymakers estadounidenses (Loveman, 2010).

Sumado a lo anterior está el hecho indiscutible de que la llamada guerra contra las drogas adquirió un nuevo impulso luego de los atentados terroristas del 11 de septiembre de 2001 en Nueva York. A partir de este hecho, el conjunto de iniciativas adoptadas por Estados Unidos para enfrentar las amenazas terroristas sumaba al narcotráfico como una amenaza equivalente a la que podían causar grupos extremistas islámicos, por lo que el combate contra los narcotraficantes operaría desde Estados Unidos bajo la lógica de la guerra contra el terrorismo.

La simbiosis conceptual de este problema se expresa en el concepto de narcoterrorismo, el cual supone, como señala Mantilla-Valbuena, que "existe una única amenaza la cual contiene de manera simultánea y unívoca a las dos fuentes de inseguridad más peligrosas del planeta y, en consecuencia, las convierte de manera indiscriminada en un único objetivo susceptible de ser atacado a través de una misma estrategia política y militar" (2008:250). Esta suposición referente a que ambos fenómenos son reductibles a una misma lógica política, económica y criminal que puede ser abordada bajo una misma estrategia, ha hecho más compleja y difusa la comprensión del fenómeno del narcotráfico.

${ }^{11}$ Otros aspectos que justifican esta mala evaluación apuntan a que los niveles de consumo continúan expandiéndose en América Latina mientras tienden a estabilizarse en América del Norte y Europa; el aumento del crimen organizado y de violencia contra jóvenes y pobres; la criminalización de la política y la politización del crimen; la corrupción de los funcionarios públicos, del sistema judicial, de los gobiernos, del sistema político y, en particular, de las fuerzas policiales encargadas de mantener la ley y el orden. 
Esta nueva concepción surgida de la conjunción de dos guerras (contra el tráfico de drogas y contra el terrorismo), se plasma en términos concretos en que Colombia queda como el foco de agrupaciones terroristas, como ya lo analizaba el Transnational Intitute en diciembre de 2001 al señalar que

[...] después del 11 de septiembre las FARC resultan más interesantes para EEUU como terroristas que como narcotraficantes. En cualquier caso buscan su aniquilación, pero si el acento se pone en el terrorismo de las FARC, si los fondos se destinan claramente en esta dirección, la guerra antidroga —en el área del narcotráfico- corre el riesgo de sufrir las consecuencias. Una aniquilación de las FARC no significaría la aniquilación del narcotráfico colombiano ni mucho menos. No son las FARC sino los diversos cárteles que operan en el país el verdadero motor del negocio de las drogas (Armenta et al., 2001:6-7).

$\mathrm{Al}$ analizar la dinámica que permitió la emergencia de la guerra contra las drogas, Jeslman señala que "en retrospectiva, la guerra contra las drogas podría verse como una transición entre la guerra fría y la guerra contra el terrorismo en lo que se refiere a legitimar las operaciones, bases e intervenciones militares en el exterior" (2011:7), donde el escenario principal de operaciones militares era América Latina y muy especialmente Colombia, como señalábamos al comienzo de este apartado.

La dinámica resultante de esta lucha contra el narcotráfico en países como México da cuenta precisamente de la complejidad del fenómeno y de los malos resultados que ha tenido la militarización de esta lucha. Sólo para ilustrar, podemos mencionar las altas tasas de homicidio en ese país, luego de la militarización que emprendió el presidente de México Felipe Calderón a partir del año 2006 y que tiene como saldo más de 42000 personas muertas hasta el año 2011 (JSO, 2011).

Sin embargo, esta apuesta militar para el combate al tráfico ilícito de drogas está teniendo, al parecer, un viraje inesperado. Como señala Bewley-Taylor, este cambio es fruto de la convicción de que

[...] en materia de políticas nacionales, los enfoques no punitivos, pragmáticos y orientados a la salud que están en sintonía con las normas fundamentales de los derechos humanos abordan mejor actuales tratados internacionales; tratados que, en su mayor parte, fueron negociados y adoptados en una época en 
que tanto el mercado ilícito como los conocimientos sobre su modo de operar tenían poco que ver con los de hoy día (Bewley-Taylor, 2011:1).

Una clara demostración de esta tendencia la ha dado recientemente el propio presidente de Colombia, Juan Manuel Santos, quien en la reciente cumbre de la Comunidad de Estados Latinoamericanos y Caribeños (CELAC) en Chile volvió a plantear la necesidad de que los gobiernos de América Latina y Europa analicen los resultados del estudio que la Organización de Estados Americanos (OEA) está haciendo sobre el tema de las drogas. ${ }^{12}$

\section{El tráfico de drogas en Chile y su expresión en el Norte Grande ${ }^{13}$}

Como problemática de seguridad, los estudios en torno al tráfico ilícito de drogas en nuestro país resultan más bien escasos. La mayoría de los existentes se centra en las problemáticas de salud en torno a los consumidores y en los efectos asociados al entorno familiar, laboral y social más inmediato del consumidor de drogas. En esa línea se encuentran numerosos estudios impulsados por entidades de gobierno, como por ejemplo los del actual Servicio Nacional para la Prevención y Rehabilitación del Consumo de Drogas y Alcohol (Chile, G. d.) (ex CONACE), entidad del gobierno de Chile responsable de elaborar las políticas de prevención del consumo de drogas y alcohol, así como del tratamiento, rehabilitación y reinserción social de las personas afectadas por estas sustancias. ${ }^{14}$ Dentro de los trabajos permanentes de este servicio destacan los estudios sobre las drogas en población general (desde el año 1994) y población escolar (desde el año 1995); asimismo, es posible encontrar algunos estudios que relacionan el consumo de drogas con la salud, la comisión de delitos y la juventud. Sin

${ }^{12}$ Ver más en <http://www.bbc.co.uk/mundo/noticias/2013/01/130130_colombia_droga_sinteticas_dp.shtml>: "Colombia abre debate sobre legalización de drogas sintéticas", ввс Mundo, 30 de enero de 2013.

${ }^{13}$ Hacemos alusión con Norte Grande a las regiones de Arica-Parinacota, Tarapacá y Antofagasta.

${ }^{14}$ Para conocer en detalle esos trabajos consúltese la página $<$ http://www.senda.gob. $\mathrm{cl} /$ observatorio/estudios/ $>$. 
embargo, sobre la problemática puntual del narcotráfico no existen trabajos que aborden la situación a nivel nacional, salvo los reportes de los Carabineros de Chile y de la Policía de Investigaciones en relación con los procedimientos policiales que practican. Lo anterior podría explicarse por el hecho de que en Chile la problemática central sobre las drogas está orientada a frenar el consumo, y como consecuencia la dictación de una nueva ley de drogas, con figuras especiales, mayor graduación de penas, sanciones especiales a funcionarios públicos y miembros de las FFAA y la creación de una nueva figura penal en materia de legislación, la del microtráfico, como opción punitiva al tráfico de pequeñas cantidades; aunque se reconoce que el incremento de decomisos de drogas (como veremos más adelante) da cuenta de que Chile se ha convertido de manera progresiva en un país de tránsito de drogas ilegales.

Si bien los delitos asociados a la Ley de Drogas (Ley 20000) y que incluyen tráfico, consumo, cultivo, órdenes de aprehensión y otras no están incorporados como delitos de mayor connotación social (DMCS), es evidente que dicha problemática resulta de enorme trascendencia para las políticas de seguridad pública en nuestro país, pues sus estadísticas son sistematizadas y analizadas en los informes trimestrales y anuales de los procedimientos policiales por infracción a la Ley de Drogas, ${ }^{15}$ elaborados por la División de Seguridad Pública del Ministerio del Interior.

En este marco, la situación del tráfico de drogas adquiere una singular particularidad para la triple frontera que analizamos, pues en términos de la comisión de delitos asociados al tráfico de drogas y el decomiso de ellas en procedimientos policiales, las tres primeras regiones del norte de nuestro país son muy significativas para las estadísticas policiales, llevándose estas regiones la mayor asignación de recursos financieros del Estado para adquisición de equipo y armamento especializado y de funcionarios policiales para su persecución. Además, la singularidad de estas regiones, y particularmente la de Tarapacá, está dada por la enorme cantidad de población penal encarcelada por tráfico de drogas, en comparación a otros delitos de mayor connotación social. A continuación revisaremos las características que adquiere esta problemática a escala regional en un ejercicio comparado con las estadísticas nacionales.

${ }^{15}$ Desde el año 2005 esta problemática es objeto de un informe especializado por parte de esta división de gobierno. 


\section{Procedimientos policiales, el accionar de la justicia y la población penal en Tarapacá: el Norte Grande y las características del tráfico de drogas}

En términos estadísticos son tres las fuentes que a nuestro juicio requieren analizarse para comprender la dimensión de la problemática delictual del tráfico de drogas en la región de Tarapacá. La primera fuente es la registrada por el Ministerio del Interior y tiene que ver con los procedimientos policiales, ${ }^{16}$ que para este trabajo se consideran sólo los relacionados con los decomisos de pasta base (PBC) y de clorhidrato de cocaína (CLC). ${ }^{17}$ Así, la situación a nivel nacional y regional en el periodo 2003-2010 es la que se muestra en el cuadro 1.

Las regiones Metropolitana, de Tarapacá y Arica y Parinacota lideran el decomiso de clorhidrato de cocaína con $33.4 \%, 23.7 \%$ y $16.3 \%$ del total de decomisos efectuados entre los años 2003-2010 (20 862 kg), destacándose la región de Arica y Parinacota como la única que tiene una tendencia al alza desde el año 2007. Es posible suponer que con anterioridad al año $2007^{18}$ Arica y Parinacota tenía la misma importancia en el decomiso de drogas, pues como se observa en la gráfica 1, el decomiso de drogas en Tarapacá cae de manera importante.

En el decomiso de pasta base de cocaína la situación no es tan diferente respecto al de la cocaína, en relación con la importancia de las regiones del norte del país y la región Metropolitana. La singularidad está dada por la importancia que adquiere la región de Antofagasta en el decomiso total de esta droga, pues encabeza el lugar de las regiones con mayores decomisos con $33.1 \%$, correspondiente a $12420 \mathrm{~kg}$; mientras que la región de Tarapacá alcanza el segundo lugar con $9847 \mathrm{~kg}$ (26.3\%), tal como se aprecia en el cuadro 2.

16 "Designa las operaciones realizadas por ambas policías, Gendarmería de Chile y el Servicio Nacional de Aduanas, en el marco de las infracciones a la Ley de Drogas, con resultado de decomisos y/o detenciones, que son informados a la División de Seguridad Pública del Ministerio del Interior, a través de un instrumento diseñado para tal efecto" (Interior, 2011:2).

${ }^{17}$ No se consideran relevantes por su escaso número de drogas incautadas como marihuana y otros fármacos, por ser poco significativas en el volumen total de decomisos de drogas.

${ }^{18}$ Año en que se crea la región de Arica y Parinacota. 
Cuadro 1. Decomisos de clorhidrato de cocaína, periodo 2003-2010

\begin{tabular}{|l|c|c|}
\hline \multicolumn{1}{|c|}{ Regiones } & $\mathrm{Kg}$ & $\%$ \\
\hline Arica y Parinacota* & 3397,1 & $16,3 \%$ \\
\hline Tarapacá & 4944,7 & $23,7 \%$ \\
\hline Antofagasta & 2903,4 & $13,9 \%$ \\
\hline Atacama & 580,8 & $2,8 \%$ \\
\hline Coquimbo & 648,1 & $3,1 \%$ \\
\hline Valparaíso & 734,5 & $3,5 \%$ \\
\hline Metropolitana & 6966,4 & $33,4 \%$ \\
\hline O'Higgins & 30,4 & $0,1 \%$ \\
\hline Maule & 54,8 & $0,3 \%$ \\
\hline Bíobio & 554,4 & $2,7 \%$ \\
\hline Araucanía & 21,5 & $0,1 \%$ \\
\hline De Los Ríos & 6,1 & $0,0 \%$ \\
\hline De Los Lagos & 19,4 & $0,1 \%$ \\
\hline Aysén & 0,4 & $0,0 \%$ \\
\hline Magallanes & 20862,9 & $100,0 \%$ \\
\hline Total & & \\
\hline
\end{tabular}

* Comprende sólo el periodo 2008-2010, desde su creación como región.

Fuente: Elaboración propia. Fiscalía Regional de Tarapacá. 


\section{Gráfica 1. Decomisos de clorhidrato de cocaína por regiones, periodo 2003-2010}

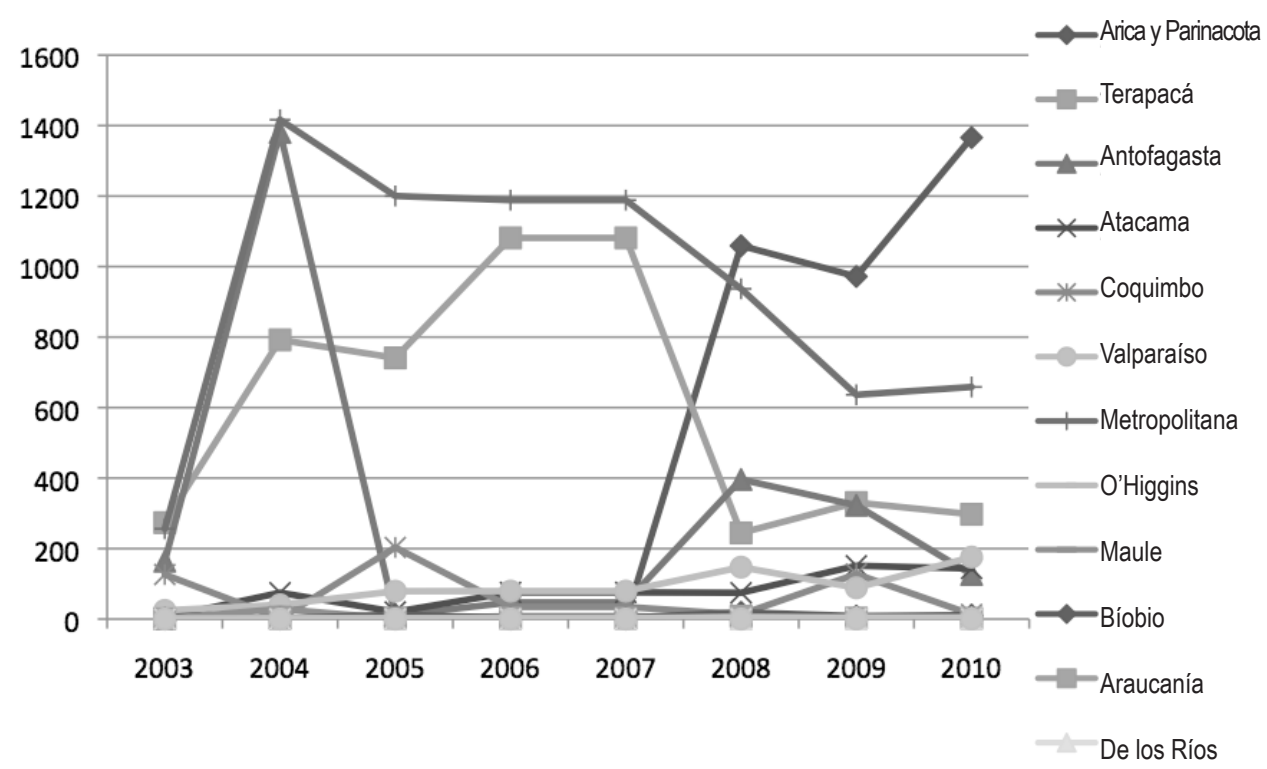

Fuente: Elaboración propia. Ministerio del Interior, gobierno de Chile.

En relación con las tendencias en el decomiso de $\mathrm{PBC}$, la diferencia respecto al de la CLC está en que todas las regiones con mayores decomisos, a excepción de Antofagasta, tienden al incremento progresivo, sin sobrepasar el promedio general de dos toneladas anuales, mientras que la región de Antofagasta tuvo un incremento sustantivo en el año 2007, para decrecer posteriormente (gráfica 2).

Como puede apreciarse, la relevancia que tienen las regiones del norte de nuestro país más la región Metropolitana es significativa pues constituye, tanto en los decomisos de PBC como en los de CLC, más de $80 \%$ de las incautaciones a escala nacional, contribuyendo sólo las tres primeras regiones del norte de Chile, en orden geográfico, con $52.9 \%$ en CLC y con $62.9 \%$ en PBC. Como primera conclusión, es evidente que la importancia que adquieren las regiones del norte del país en los decomisos de droga está asociada al papel que desempeñan como regiones de paso, pues la cantidad de drogas incautadas no tiene ninguna proporción con el mercado local de consumo, como sí podría tener la región Metropolitana y su población. 
Cuadro 2. Decomisos de clorhidrato de cocaína, periodo 2003-2010

\begin{tabular}{|l|c|c|}
\hline \multicolumn{1}{|c|}{ Regiones } & $\mathrm{Kg}$ & $\%$ \\
\hline Arica y Parinacota* & 1311,1 & $3,5 \%$ \\
\hline Tarapacá & 9846,8 & $26,3 \%$ \\
\hline Antofagasta & 12420,4 & $33,1 \%$ \\
\hline Atacama & 1771,6 & $4,7 \%$ \\
\hline Coquimbo & 1890,7 & $5,0 \%$ \\
\hline Valparaíso & 1226,7 & $3,3 \%$ \\
\hline Metropolitana & 8122,7 & $21,7 \%$ \\
\hline O'Higgins & 231,6 & $0,6 \%$ \\
\hline Maule & 165,3 & $0,4 \%$ \\
\hline Bíobio & 499,8 & $1,3 \%$ \\
\hline Araucanía & 2,1 & $0,0 \%$ \\
\hline De Los Ríos & 8,2 & $0,0 \%$ \\
\hline De Los Lagos & 10,9 & $0,0 \%$ \\
\hline Aysén & 0,0 & $0,0 \%$ \\
\hline Magallanes & 37507,9 & $100 \%$ \\
\hline Total & 0,0 & \\
\hline
\end{tabular}

* Comprende sólo el periodo 2008-2010, desde su creación como región.

Fuente: Elaboración propia con base en las estadísticas del Ministerio del Interior. 


\section{Gráfica 2. Decomisos de pasta base de cocaína por regiones}

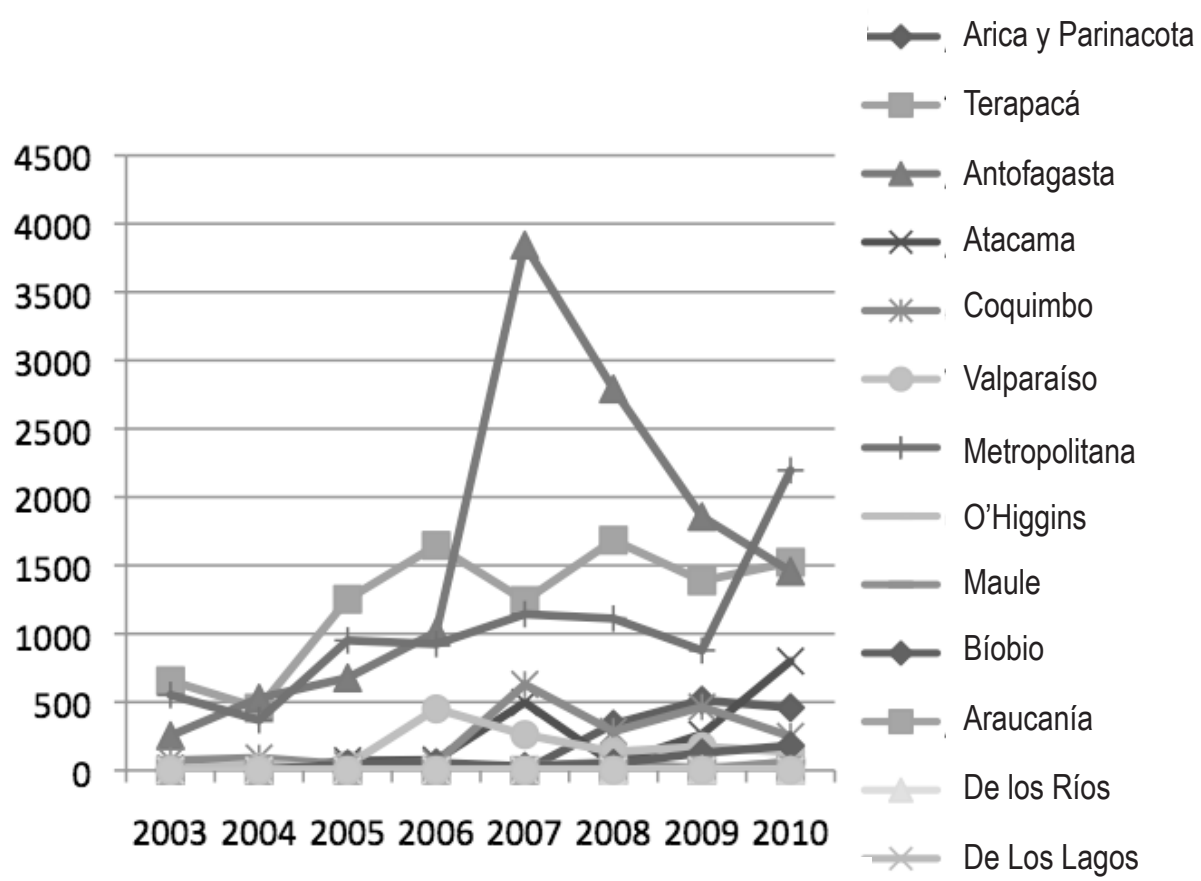

Fuente: Elaboración propia. Ministerio del Interior.

\section{El Ministerio Público y el tráfico de drogas en la provincia del Tamarugal}

Hasta ahora hemos hablado en términos generales de la región de Tarapacá como espacio fronterizo. Sin embargo, en estricto rigor geográfico, en términos de la división político-administrativa, el territorio fronterizo con Bolivia corresponde a la provincia del Tamarugal. Siguiendo este argumento y vinculándolo con las características históricas y socioculturales de este territorio, es que hemos delimitado el análisis estadístico de la población penitenciaria y los procedimientos penales a esta provincia.

Dicho lo anterior, analizaremos a continuación los datos entregados por la Fiscalía Regional de Tarapacá y Gendarmería de Chile. 
En lo que respecta al número de procedimientos penales terminados o suspendidos que fueron impulsados por la Fiscalía Local de Pozo Almonte (fiscalía que abarca las infracciones penales cometidas en la provincia del Tamarugal), el número más significativo de ilícitos penales corresponde a aquellos delitos contenidos en el Decreto Ley 1094 de Extranjería ${ }^{19}$ que alcanzan $37.8 \%$. Le siguen en número de casos los delitos asociados al tráfico y consumo de drogas con $28.8 \%$, y en tercer lugar se encuentran las infracciones de fraude y contrabando con 19.9\%. De los delitos comunes el que aparece con mayor frecuencia es el robo de vehículos con un 3.9\%, delito asociado por la prensa regional al tráfico de estupefacientes, pero que en definitiva en pocas ocasiones se ha transformado en asociación ilícita en un contexto de investigación por tráfico. El cuadro 3 da cuenta de la distribución porcentual de los demás delitos que resulta ser muy poco significativa en relación con los delitos comentados con anterioridad.

Respecto del número total de procedimientos penales seguidos por la Fiscalía Local de Pozo Almonte durante el periodo 2003-2009 podemos afirmar que se sigue una tendencia creciente que no sobrepasa los 500 casos anuales. Si relacionamos este número de casos con el total de personas imputadas las tendencias difieren, pues mientras los procedimientos aumentan, el número de imputados disminuye, tal como se aprecia en la gráfica 3.

En cuanto al número de extranjeros formalizados por la comisión de algún delito en el territorio analizado, las estadísticas arrojan una participación significativa de población boliviana la cual alcanza 39\%, siendo mayoritaria la población chilena con 50\%; Perú y Colombia le siguen en importancia en la participación de extranjeros con $3 \%$ y $1 \%$ respectivamente.

Si analizamos la distribución de los delitos cometidos por los imputados de nacionalidad boliviana, podemos observar que en su mayoría han

${ }^{19}$ La ley señala sobre las infracciones: "Artículo 68.- Los extranjeros que ingresen al país o intenten egresar de él, valiéndose de documentos falsificados, adulterados o expedidos a nombre de otra persona o hagan uso de ellos durante su residencia, serán sancionados con presidio menor en su grado máximo, debiendo disponerse, además, su expulsión, la que se llevará a efecto tan pronto el afectado cumpla la pena impuesta".

"Artículo 69.- Los extranjeros que ingresen al país o intenten egresar de él clandestinamente, serán sancionados con la pena de presidio menor en su grado máximo. Son aquellos delitos asociados al ingreso clandestino al país, con documentación falsificada, por lugares no habilitados, etc." (Chile, E. d., 1975). 


\section{Cuadro 3. Distribución de categorías de delitos en casos terminados o suspendidos}

\begin{tabular}{|l|c|c|}
\hline & Núm. de casos & $\%$ \\
\hline Delitos Ley de Estranjería & 1065 & $37,8 \%$ \\
\hline Delitos Ley de Drogas & 1047 & $37,2 \%$ \\
\hline $\begin{array}{l}\text { Infracc. Ordenanza de Aduanas } \\
\text { (fraude y contrabando) Artículo 176 }\end{array}$ & 561 & $19,9 \%$ \\
\hline Robo de vehículo motorizado & 109 & $3,9 \%$ \\
\hline Abigeato & 25 & $0,9 \%$ \\
\hline Delitos marcarios & 5 & $0,2 \%$ \\
\hline Delitos contra la Ley de Propiedad Industrial & 4 & $0,1 \%$ \\
\hline $\begin{array}{l}\text { Falsificación o uso de pasaporte } \\
\text { o permiso para porte de armas }\end{array}$ & 1 & $0,0 \%$ \\
\hline Total & 2817 & \\
\hline
\end{tabular}

Fuente: Elaboración propia. Fiscalía Regional de Tarapacá.

Gráfica 3. Secuencia temporal de procedimientos penales e imputados, años 2003-2009

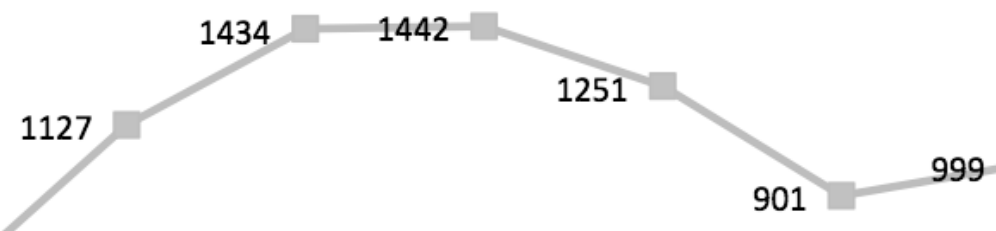

615

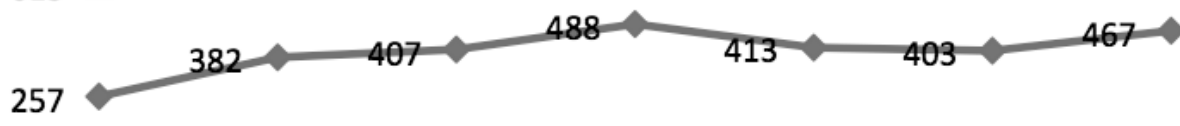

\begin{tabular}{|c|c|c|c|c|c|}
\hline & 2004 & 2005 & 2006 & 2007 & 2008 \\
\hline
\end{tabular}

Fuente: Elaboración propia. Fiscalía Regional de Tarapacá. 
sido judicializados por infracciones delictuales contenidas en el Decreto Ley 1094 de Extranjería con 74\%. Le siguen los delitos de fraude y contrabando con 14\%, mientras que el tráfico ilícito de drogas alcanza sólo $7 \%$ de los bolivianos imputados.

La distribución de nacionalidades en el delito de tráfico de drogas es de $22 \%$ para personas bolivianas y $68 \%$ para los nacionales, mientras que las personas de origen peruano alcanzan sólo 6\%. Para los delitos relacionados con la Ley de Extranjería la participación de bolivianos y chilenos se invierte, con $59 \%$ para los primeros y $25 \%$ para los segundos; mientras que para los peruanos es de $5 \%$ (gráfica 4 ).

\section{Población penal en el Centro de Detención Preventiva de Pozo Almonte}

Al revisar las estadísticas entregadas por la Gendarmería de Chile es posible apreciar una distribución relativamente equitativa de tres grandes categorías de delitos: leyes especiales ${ }^{20}$ y tráfico de drogas con $32 \%$ cada una, y delitos contra las personas ${ }^{21}$ con $27 \%$ (gráfica 5).

Al revisar la distribución de la población penal condenada según nacionalidad, resulta asombroso encontrar un altísimo porcentaje de bolivianos (11\%), en comparación con las otras nacionalidades existentes en el penal de Pozo Almonte, siendo mayoritaria la población chilena con $87.3 \%$, como se aprecia en el cuadro 4.

Sin embargo, más llamativo resulta analizar la composición de la población condenada por tráfico de drogas, pues la participación de bolivianos alcanza $89 \%$, superando a la población peruana y a cualquier otra nacionalidad, lo que se aprecia en la gráfica 6 .

Si ponemos atención en la población boliviana recluida en el penal de Pozo Almonte, podemos apreciar que $87 \%$ de los condenados, lo está por tráfico de drogas. A su vez, de los bolivianos condenados por tráfi-

${ }^{20}$ Comprenden delitos por infracciones de tránsito, manejo en estado de ebriedad, contrabando, ebriedad, maltrato de obra a carabineros, infracciones contra la ley de alcoholes, porte ilegal de armas de fuego y violencia intrafamiliar, entre otras.

${ }^{21}$ Comprenden delitos por homicidios, hurtos, lesiones, cuasidelitos de homicidio y lesiones, riñas, robo y violación. 
Gráfica 4. País de nacimiento de imputados por infracciones penales en la provincia del Tamarugal, periodo 2003-2009

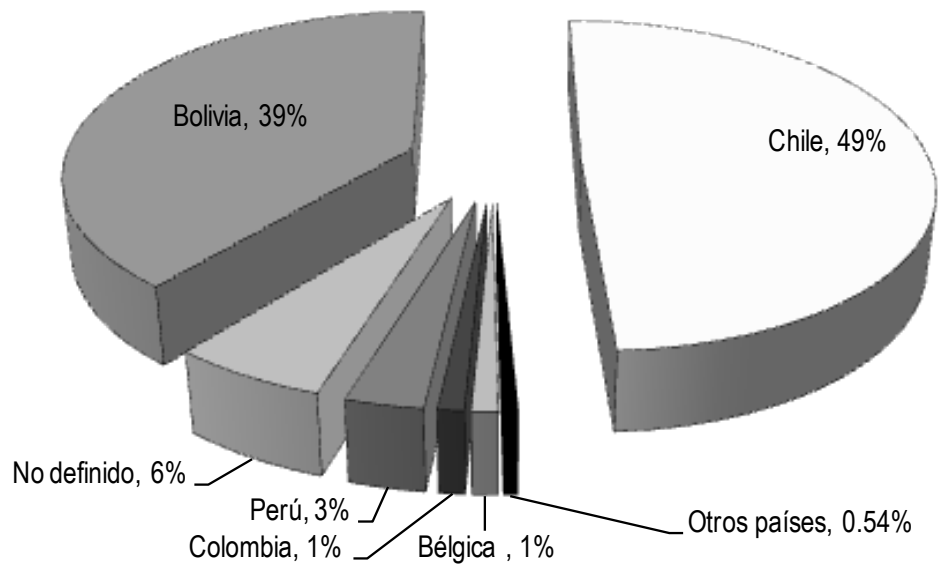

Fuente: Elaboración propia. Fiscalía Regional de Tarapacá.

Gráfica 5. Distribución de la población de condenados cdp Pozo Almonte, según categorías de delitos, años 2000-2009
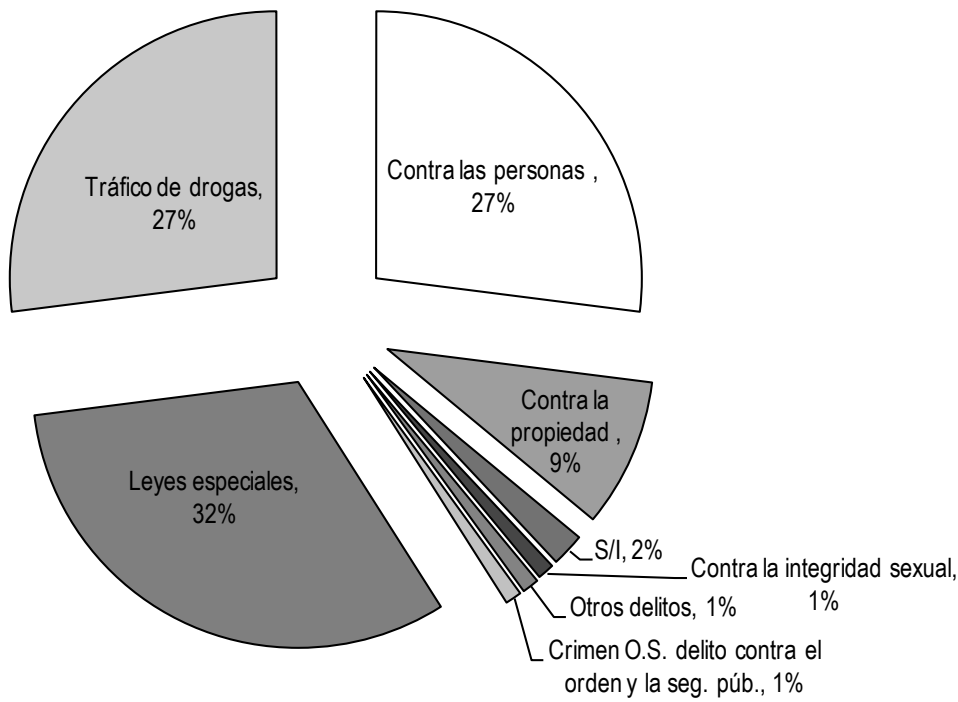

Fuente: Elaboración propia. Gendarmería de Chile. 


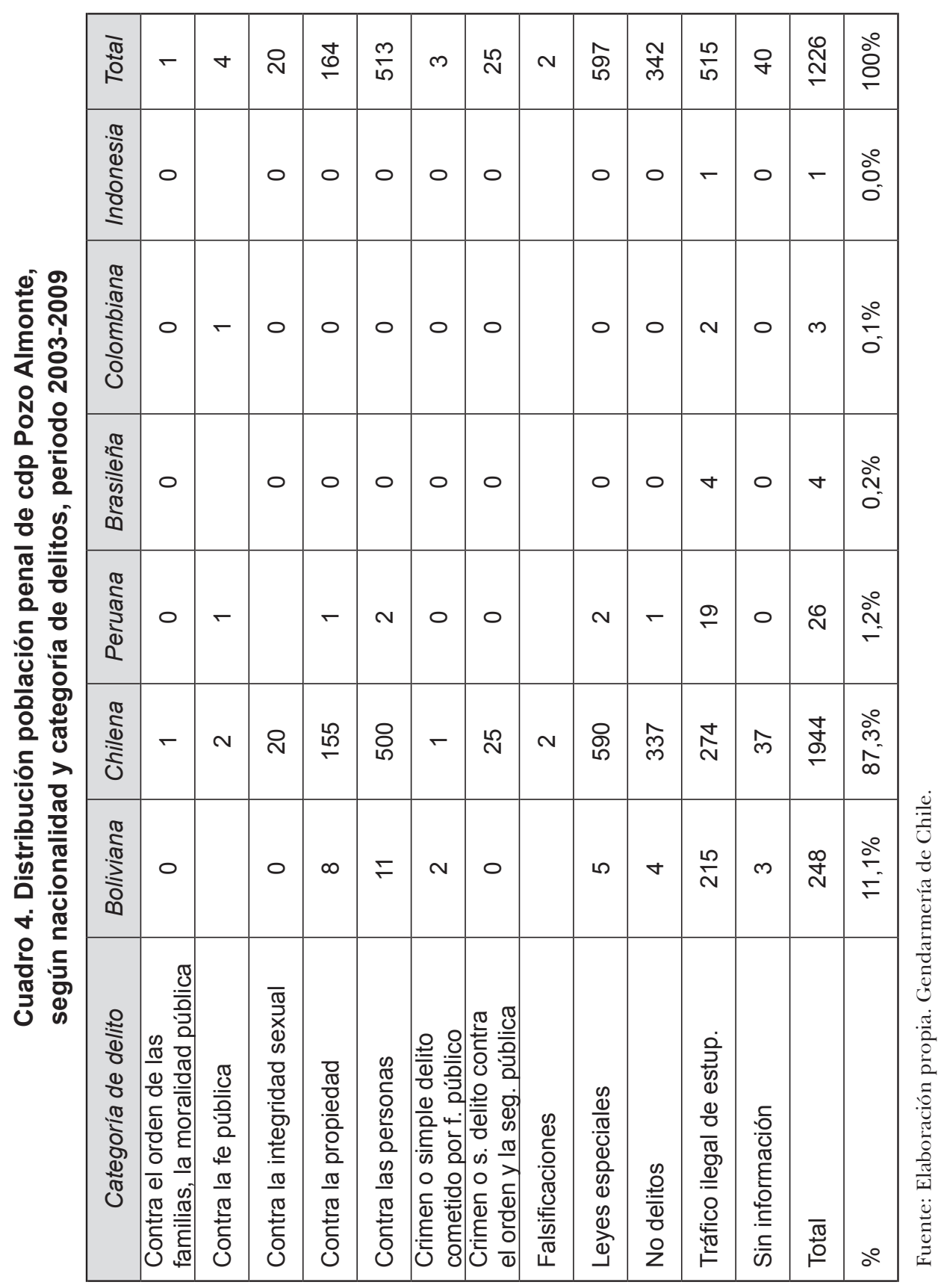




\section{Gráfica 6. Distribución de condenados extranjeros cdp Pozo Almonte, por delitos asociados al tráfico de drogas, periodo 2000-2009}

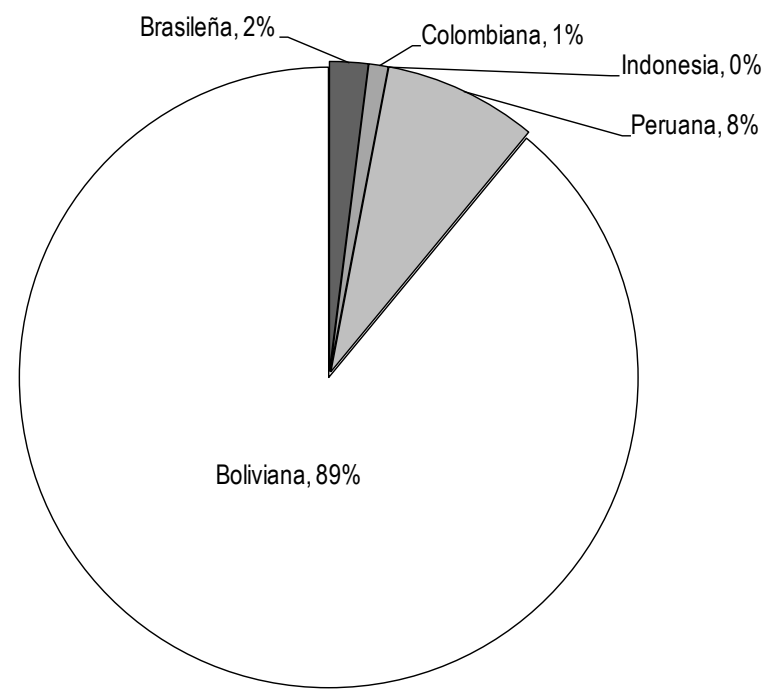

Fuente: Elaboración propia. Gendarmería de Chile.

co de drogas, $35 \%$ se autoidentifica como indígena (24\% aymara y $11 \%$ quechua). ${ }^{22}$ Lo anterior da cuenta de que la participación de población extranjera fronteriza resulta altamente significativa y más aún resulta su condición de pertenencia a pueblos indígenas. Esto nos puede dar luces sobre lo señalado al comienzo de este trabajo respecto de los flujos permanentes de personas y mercancías en este espacio de frontera, que sumados a la rearticulación de las redes criminales asociadas al tráfico de drogas están incidiendo directamente en la criminalización de población transfronteriza. Si asociamos las estadísticas de la población penal de Pozo Almonte con las que nos entrega el Ministerio Público (gráfica 7), podemos darnos cuenta de que el alto número de bolivianos y peruanos en la participación de ilícitos de tráfico de drogas es significativa, y probablemente responde tanto a una estrategia de las redes criminales internacionales como a las particularidades y ventajas que entrega este espacio fronterizo.

${ }^{22}$ Cabe señalar que del total de condenados por tráfico de drogas, $32 \%$ se autoidentifica como indígena (básicamente quechua o aymara). 


\section{Gráfica 7. Edad promedio población condenada cdp de Pozo Almonte, según nacionalidad, periodo $2000-2010$}

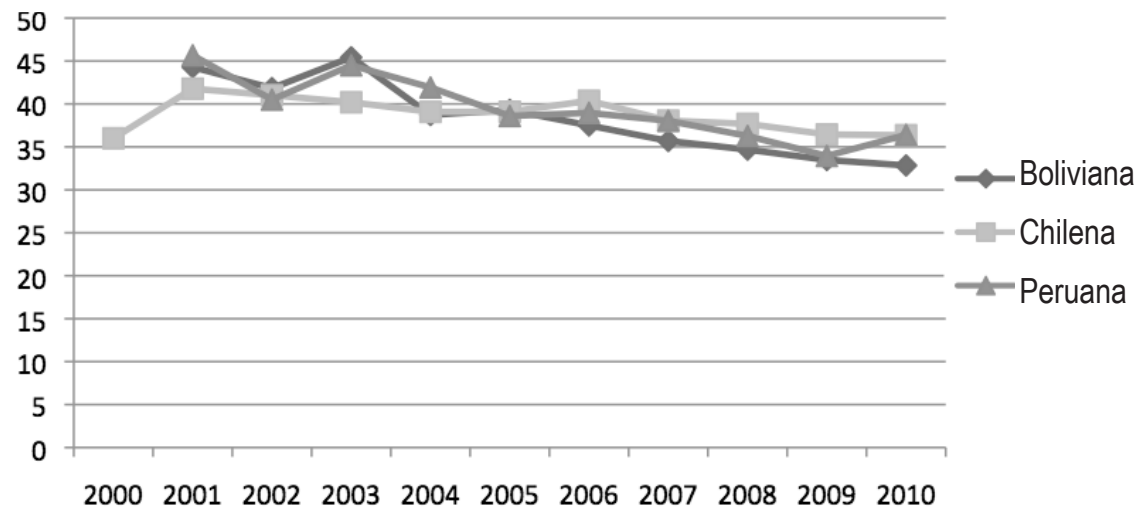

Fuente: Elaboración propia. Gendarmería de Chile.

Si analizamos las características demográficas de la población condenada por tráfico de drogas, podemos apreciar la disminución progresiva del promedio de edad tanto en la población extranjera como en la nacional, siendo muy significativa la disminución en la población boliviana, la que desde el año 2001 al 2010 vio reducido su promedio en más de 12 años - para los peruanos se ha reducido en nueve años y para los chilenos en seis años- Lo anterior evidentemente no resulta casual y podría deberse a las estrategias de las redes criminales que apuntan cada vez más a una población más joven dispuesta a correr el riesgo en un negocio que puede resultar altamente rentable en términos económicos.

En relación con la distribución por sexo de los condenados por tráfico de drogas, la participación femenina resulta muy reducida con sólo 4.9\%, lo que se explica en parte porque la población penitenciaria femenina está recluida casi en su totalidad en el Centro de Cumplimiento Penitenciario de Iquique. De hecho no existen ingresos de mujeres condenadas en el CDP de Pozo Almonte desde el año 2007.

En términos de instrucción escolar, para las tres nacionalidades mencionadas, los condenados sin instrucción no sobrepasan $5 \%$, mientras que más de $80 \%$ de los condenados de estas nacionalidades tiene instrucción básica y/o media. Resulta destacable sí, que de la población peruana $16 \%$ posee enseñanza superior. 


\section{Reflexiones finales}

Las transformaciones debidas al proceso de la globalización y sus impactos en la economía, los medios de comunicación, las tecnologías y por supuesto en las comunidades de frontera, en ese sentido la particular conformación del territorio nacional en el Norte de Chile, otorgan mayor singularidad al espacio fronterizo de Tarapacá. Los agentes del Estado primero, para la constitución de una identidad nacional, y luego el papel de los actores regionales en procesos de integración transfronteriza, requieren de un análisis singular de Tarapacá y de cómo fenómenos como el narcotráfico afectan a la región objeto de este estudio.

La historia regional que destaca los movimientos migratorios, los flujos de personas y mercancía de uno y otro lado de la frontera, ha entregado particulares condiciones para que la situación del narcotráfico en Tarapacá y el Norte Grande en general sea sustancialmente distinta a otras zonas del país. Las estadísticas revisadas así lo demuestran.

Las transformaciones de los Estados-nación en relación con los espacios de soberanías y de espacios transfronterizos son elementos comprensivos que permiten dar luces sobre las nuevas dinámicas que adquiere la delincuencia internacional, particularmente los traficantes de drogas. Asociado a ello está el hecho de que el mercado de drogas en el ámbito internacional está fuertemente influenciado por las orientaciones militares de lucha contra el narcotráfico, lo que ha conllevado la aparición de nuevas estrategias delictuales para la distribución de droga, con sus consiguientes efectos sobre Chile como alternativa para el tránsito de drogas a mercados internacionales.

Sin embargo, estas nuevas estrategias no sólo quedan a nivel delictual, pues junto con ellas va la continua modificación legislativa con penas más duras y mecanismos de investigación que validan tipos de actuaciones cada más insólitas en pos del combate al tráfico de estupefacientes, facultades de fiscalización a las policías y gastos estatales impensados en técnicas de investigación y armamento.

Con la evidencia que nos entregan las estadísticas policiales analizadas en este trabajo resulta indiscutible que el Norte Grande de Chile se ha convertido en los últimos diez años en el más importante territorio de ingreso y tránsito de drogas ilegales (fundamentalmente el clorhidrato 
de cocaína y la pasta base de cocaína), concentrando las tres regiones del norte del país $55.4 \%$ de CLC y 62.9 de PBC en el periodo 2003-2010. También es posible distinguir de estas estadísticas una diferenciación entre regiones nortinas respecto del tipo de droga decomisada (CLC en AricaParinacota y $\mathrm{PBC}$ en las regiones de Tarapacá y Antofagasta). Lo anterior da cuenta también de que la región Metropolitana sigue en importancia en cuanto al decomiso de estos dos tipos de droga; sin embargo, podemos relacionar el significativo número de drogas decomisadas en esta región con un importante mercado de consumidores, lo que no quita que un número considerable de la droga decomisada tuviera como destino mercados internacionales (sobre todo Europa, según las fuentes policiales) -lamentablemente no tenemos indicios de cuál es la proporción de decomisos que tendría ese destino. ${ }^{23}$

En relación con el actuar del Ministerio Público en la provincia del Tamarugal, resulta muy significativo apreciar que hay una mayor persecución penal dirigida al tráfico de drogas y a delitos asociados a infracciones a la Ley de Extranjería (ambos con 37\%); donde los principales inculpados son ciudadanos bolivianos (59\%) — mientras que los chilenos representan $25 \%$ de imputados en casos terminados o suspendidos-. Respecto del número de inculpados por tráfico de drogas, las proporciones son similares a las de la población penal del Centro de Detención Preventiva de Pozo Almonte; esto es, $78 \%$ son chilenos, $14 \%$ son bolivianos y $4 \%$ son peruanos.

La composición de la población penal de Pozo Almonte, tanto las particularidades del espacio de frontera que agrupa, en tanto da cuenta de una importante proporción de extranjeros de países fronterizos como Bolivia y Perú, como así también de la dinámica delictual fronteriza concentrada en delitos de narcotráfico y los vinculados a la Ley de Extranjería. Asimismo, la distribución de los delitos cometidos nos da muestras de tendencias relativamente distintas entre la población nacional y extranjera, donde esta última se concentra en delitos asociados al tráfico de drogas como al tránsito de personas en la frontera (delitos contra la Ley de Extranjería). La alta pro-

${ }^{23}$ En el Plan Frontera Norte se señala que "según informaciones del Servicio Nacional de Aduanas y de las policías chilenas, ese mismo año (2005) se detectaron siete embarques de cocaína en el mundo provenientes de puertos chilenos, en especial del puerto de Arica, totalizando en su conjunto cerca de 2.5 toneladas de drogas, las que estaban ocultas en cargas con mercancía boliviana en tránsito" (Chile, G. d., 2011). 
porción de condenados de nacionalidad boliviana respecto de la población extranjera y el delito de tráfico de drogas en particular, resulta muy preocupante pues puede estar evidenciando la estrategia de las redes criminales para el ingreso de drogas desde ese país, en tanto tercer productor mundial de cocaína, pero también muestra indicios de que esta región y el norte de Chile en general son territorios difíciles de controlar por las policías chilenas. Precisamente, el recientemente lanzado Plan Frontera Norte (Chile, G. d., 2011), impulsado por el Ministerio del Interior del gobierno de Chile, apunta a mejorar los resultados de control policial en esa línea.

Particular preocupación habría de causar para las políticas de gobierno, el efecto criminalizador que puede generarse frente a la población migrante boliviana y su participación en ilícitos como el tráfico de drogas. Resulta fundamental realizar una distinción entre lo que ocurre en los espacios rurales como la provincia del Tamarugal, y lo que sucede en los espacios urbanos donde la evidencia indica que el tráfico y microtráfico está protagonizado en su gran mayoría por chilenos.

Finalmente, queda como desafío para estudios posteriores el análisis sobre la feminización de los traficantes y microtraficantes, pues los estudios indican que en los últimos diez años la participación de mujeres en la internación de drogas en el país ha ido en aumento, así como la de mujeres microtraficantes en sectores urbanos.

\section{Bibliografía}

Armenta, A., Jelsma, M., Blickman, Y. y Montañés V. (2001), Afganistán, drogas y terrorismo. Fusión de dos guerras. Drogas y Conflicto. Documentos de debate, 2001(3). Disponible en: < http://www.tni.org/files/ download/200703161815326033.pdf>.

Beck, U. (2008), ¿Qué es la globalización?: falacias del globalismo, respuestas a la globalización, Barcelona, Paidós.

Bewley-Taylor, D. (2011), Hacia una revisión de las convenciones de drogas de la ONU. La lógica y los dilemas de los grupos afines, Reforma Legislativa en Materia de Drogas, Transnational Institute (19). Disponible en: < http://www.tni.org/ sites/www.tni.org/files/download/dlr19s.pdf $>$.

Briones, L., L. Núñez y V. G. Standen (2005), "Geoglifos y tráfico prehispánico de caravanas de llamas en el desierto de Atacama (norte de Chile)", Chungará (Arica), núm. 37, pp. 195-223. 
Castells, M. (1999), Globalización, identidad y Estado, Santiago de Chile, Progama Nacional de las Naciones Unidas para el Desarrollo.

Colombia, P. d. 1. R. d. (2006), Balance Plan Colombia 1999-2005, D. d. J. y. S. Departamento Nacional de Planeación.

Chile, E. d. Ley de Extranjería (1975).

Chile, G. d. SENDA (2012), Servicio Nacional para la Prevención y Rehabilitación del Consumo de Drogas y Alcohol, en <http://www.senda.gob.cl/observatorio/ estudios/>. Fecha de consulta: 9 de mayo de 2012.

Chile, G. d. (2010), Informe anual, Departamento de Extranjería y Migración. D. d. E. y. Migración.

Chile, G. d. (2011), Plan Frontera Norte, S. d. Interior.

Dammert, L. (2009), "Drogas e inseguridad en América Latina: una relación compleja”, Revista Nueva Sociedad. Democracia y Política en América Latina, núm. 222, julio-agosto de 2009. Disponible en: < http://www.nuso.org/upload/ articulos/3625_1.pdf $>$.

De Rementería, I. (2009), "La guerra de las drogas: cien años de crueldad y fracasos sanitarios", Revista Nueva Sociedad. Democracia y Política en América Latina (222). Disponible en: < http://www.nuso.org/upload/articulos/3622_1. pdf $>$.

Devés, E. (2002), Los que van a morir te saludan: historia de una masacre, Escuela Santa María de Iquique, 1907, 4ª . edición, Santiago de Chile, Lom Ediciones.

Gavilán, V. y L. M. Tapia (2006), “Diagnóstico de los procesos migratorios en el norte de Chile”, Revista Electrónica Parinas. Revista de Cooperación Descentralizada, Internacionalización de las Regiones y Paradiplomacia, vol. II, núm. 2.

González, S. (2004), El dios cautivo: las Ligas Patrióticas en la chilenización compulsiva de Tarapacá (1910-1922), Santiago de Chile, Lom Ediciones.

(2006), "Densidad, integración y conflicto en la triple frontera (Perú, Bolivia y Chile)”, en J. A. Carnonell (ed.), Serie Integración Social y Fronteras, Bogotá, Andrés Bello.

Grimson, A. (2004), “Fronteras, naciones y región”, 28. Disponible en: < http:// www.mujeresdelsur-afm.org.uy/agenda_pos/pdf/4a_edicao/alejandro_ grimson_esp.pdf $>$.

Guillén, M. F. (2001), "Is Globalization Civilizing, Destructive or Feeble? A Critique of Five Key Debates in the Social Science Literature”, Annual Review of Sociology, núm. 27, pp. 235-260.

Gundermann, H. (1999), "Los aymaras y el tráfico regional de estupefacientes”, Manuscrito no publicado, Iquique.

Interior, M. d. (2011), Informe Nacional de Porcedimientos Policiales por Infracción a la Ley de Drogas No 20.000, D. d. S. Pública.

Jelsma, M. (2011), "El desarrollo de la fiscalización internacional de estupefacientes. Lecciones del pasado y desafíos estratégicos para el futuro”, Serie Reforma 
Legislativa en Materia de Drogas, Transnational Institute, núm 10, pp. 1-20.

JSO (2011), "Redes sociales, en la mira de los narcos", El Economista. Disponible en: <http://eleconomista.com.mx/seguridad-publica/2011/09/28/redes-socialesmira-narcos $>$.

Loveman, B. E. (2010), Adictos al fracaso. Políticas de Seguridad de Estados Unidos en América Latina y la Región Andina, Santiago de Chile, Lom Ediciones.

Mantilla-Valbuena, S. C. (2008), "Más allá del discurso hegemónico: narcotráfico, terrorismo y narcoterrorismo en la era del miedo y la inseguridad global", Papel Político, núm. 13, pp. 227-260.

Medina, E. (2006), "Aportaciones para una epistemología de los estudios sobre fronteras internacionales", Estudios Fronterizos, vol. 7, núm. 13, pp. 9-27.

Murra, J. V. (1984), "Andean Societies”, Annual Review of Anthropology, núm. 13, pp. 119-141.

- (2002), El mundo andino: población, medio ambiente y economía, Lima, Instituto de Estudios Peruanos, Pontificia Universidad Católica del Perú, Fondo Editorial.

Naciones Unidas, O. c. l. D. y. e. D. (2011), Informe mundial sobre las drogas 2010. Resumen ejecutivo. 32. Disponible en: <http://www.unodc.org/documents/ data-and-analysis/wDR2010/EXeCUTIVE_SUMMARY___SP.pdf $>$.

Sassen, S. (2007), "Una sociología de la globalización”, Análisis Político, núm. 20, pp. 3-27.

Sepúlveda, M. A., A. L. Romero y L. Briones (2005), "Tráfico de caravanas, arte rupestre y ritualidad en la Quebrada de Suca (extremo norte de Chile)", Chungará (Arica), núm. 37, pp. 225-243.

Sorj, B., I. S. d. Carvalho, M.D. d. Oliveira y R. C. Fernandes (2009), Drogas y democracia:hacia un cambio de paradigma.In C.L.s.D.y.Democracia (Eds.) Disponible en: < http://www.drogasedemocracia.org/Arquivos/livro_espanhol_04.pdf>.

Stefoni, C. (2005), "Migración en Chile”, Coleccion Ideas, año 6, núm 59. Disponible en: $<$ http://webcache.googleusercontent.com/search?q=cache:ssWV5xcl2ikJ:www. chile21.cl/temas/estudios/coleccion-ideas/page/10/+\%22MIGRACI\%C3\%93N+EN + CHILE $\% 22+$ coleccion + ideas\&cd $=1 \& \mathrm{hl}=\mathrm{es} \& \mathrm{ct}=\mathrm{clnk} \& \mathrm{gl}=\mathrm{cl}>$.

Tokatlian, J. G. (2011), "La guerra perpetua: las drogas ilícitas y el mundo andino", en C. del Arenal y M. Hirst (eds.), Pensamiento iberoamericano. Las relaciones triangulares Estados Unidos, Unión Europea y América Latina, Madrid, Agencia Española de Cooperación Internacional, Fundación Carolina.

Artículo recibido el 28 de mayo de 2012. Segunda versión aprobada el 5 de de febrero de 2013. 